\section{PERI-OPERATIVE}

TOE

\title{
The role of peri-operative transoesophageal echocardiography
}

\section{Justiaan Swanevelder ${ }^{*}$ and Alexander $\mathbf{N g}^{\#}$}

"University Hospitals of Leicester NHS Trust, Glenfield Hospital, Leicester, United Kingdom

\#Heart and Lung Centre, Royal Wolverhampton Hospitals NHS Trust, West Midlands, United Kingdom

\section{Address for correspondence:}

Dr Justiaan Swanevelder

University Hospitals of Leicester NHS Trust

Glenfield Hospital

Leicester, LE3 9QP

United Kingdom

\section{Email:}

justiaan.swanevelder@uhl-tr.nhs.uk

\section{INTRODUCTION}

In 1976 transoesophageal echocardiography (TOE) was introduced into clinical practice.( ${ }^{(1)}$ Within a decade, its use extended from cardiology departments into the cardiac surgical arena. However, at that time few probes were available for the operating theatre. Indeed in a report from the United States in 1988, only about 50 TOE probes were accessible for intra-operative use. (2) Furthermore, despite its utility for cardiac surgery, it became evident that few cardiologists were able to spend long periods in the operating theatre. Over time much enthusiasm and expertise for TOE has developed amongst cardiac anaesthesiologists, and by 200 I, 94\% of respondents in a survey of the Society of Cardiovascular Anaesthesiologists utilised intra-operative echocardiography in their routine practice. ${ }^{(3)}$

Over the past 30 years technology has improved tremendously and intra-operative TOE has become an established imaging modality and the gold standard intra-operative cardiac monitor and diagnostic tool in certain cardiac procedures, e.g. mitral valve repair, congenital heart surgery, etc.(4) There is evidence that intra-operative TOE provides valuable information which significantly influences clinical management and improves patient outcome. Several investigators have documented its benefits in critically ill patients and complex

\section{ABSTRACT}

Cardiac surgery and anaesthesia have come a long way since the late 1970s when Transoesophageal Echocardiography (TOE) was introduced into the peri-operative arena. The development of many surgical procedures and the reduction in peri-operative morbidity and mortality can be directly related to the use of TOE. In complicated surgery it has the benefit of providing real time interrogation of cardiac structures and function that can be reliable and repeatable. As with many interventions a full understanding of the limitations, possible artefacts and operating environment is required to benefit patient care. In 1996 an American Society of Anaesthesiologists/Society of Cardiovascular Anaesthesiologists Task Force published guidelines on the indications for intra-operative TOE. These published guidelines have been updated in 2003 and have recently been reviewed once again in the USA and Europe. In this document we discuss the role of peri-operative TOE and its use and value during some Category I procedures.

SAHeart 2010; 7:114-123

cardiovascular surgery. $(5,6,7,8,9,10)$ More recent retrospective analyses of prospectively collected data suggest that around $5.6 \%$ of surgical procedures are altered on the basis of intra-operative echocardiographic findings and that there are cost-benefit savings particularly during combined valve and graft operations. ${ }^{(1,12,13)}$ Recently, the roles for peri-operative echocardiography have also extended to include intensive care ${ }^{(14,15)}$ and non-cardiac surgery. ${ }^{(16,17,18)}$ Although it is complex to scientifically prove the benefits of a diagnostic monitor, TOE has been shown to strongly influence intra-operative anaesthetic decisions, particularly in patients with increased risk factors for haemodynamic instability or myocardial ischaemia. In a prospective observational case series of 98 patients undergoing abdominal surgery, the judgement of the anaesthetists was that TOE led to useful alterations in intraoperative care such as administration of fluids, vasoactive drugs and $\beta$ blockers. In some patients, use of the pulmonary artery catheter was obviated. ${ }^{(19)}$ Similarly, in another case series comprising 90 patients undergoing vascular, visceral and chest surgery, TOE directed changes in drug (47\%) and fluid therapy (24\%).(20) 


\section{PERFORMING AN INTRA-OPERATIVE TOE}

A Task Force of the American Society of Echocardiography and Society of Cardiovascular Anaesthesiologists has developed guidelines for performing a comprehensive intra-operative multiplane TOE examination based on a series of 20 anatomical crosssectional images. ${ }^{(21)}$ These guidelines promote training in TOE, assist assessment of quality and completeness of individual studies, and facilitate comparison of studies performed at different centres. A very similar set of guidelines was recommended in 2001 by the Working Group on Echocardiography of the European Society of Cardiology.(22)

Because the oesophagus is in close relationship to the left atrium and posterior aspect of the heart, a high frequency $(5 \mathrm{MHz}) 2$ dimensional (2-D) TOE transducer can provide clear images of most cardiac structures. With pulse wave (PWD) and continuous wave Doppler (CWD), blood flow velocity and direction of flow can be determined. The use of Colour-flow Doppler (CFD) adds to the ability to make a qualitative assessment of cardiac function. The multiplane facility has increased the possible 2-D views of a routine TOE examination, but still requires the examiner to mentally reconstruct a 3-dimensional (3-D) interpretation.

Recent introduction of 3-D TOE has made such reconstruction unnecessary, although the 3-D image still depends on the quality of acquired 2-D information. The spatial and temporal resolution of the new matrix array transoesophageal transducer (Philips, Andover, Massachusetts, USA) with more than 3000 piezoelectric elements, allows clear 3-D images at acceptable frame rates. A single 3-D volume acquisition over three to five cardiac cycles allows comprehensive 2-D evaluation in any plane extracted from the dataset.(23) It reduces significantly the number of steps required to complete a comprehensive examination, thus minimising examination time. (24) However, detailed quantification i.e. off line intra-operative geometric analysis using integrated 3-D mitral valve and left ventricular quantification software is slightly cumbersome. ${ }^{(25)}$ Early evidence suggests that real-time 3-D TOE adds additional information to the intra-operative comprehensive examination and decision making process during cardiac surgery.(26) In addition, 3-D images facilitate communication between the echocardiographer and other members of the surgical team. ${ }^{(27)}$ It is expected that a combined 2-D and 3-D TOE examination will, in the foreseeable future, become routine for intra-operative surgical guidance. ${ }^{(28)}$

Doppler tissue imaging (DTI) is a supplementary modality that measures myocardial velocities, strain and strain rates from specific myocardial segments. From these data, it is possible to obtain quantitative information on regional and global ventricular function as well as left ventricular filling pressure. There is debate on the utility of this information in the peri-operative period owing to dynamic alterations in myocardial loading conditions and difficulty with obtaining angle independent measurements. ${ }^{(29,30)}$ Unless the operator understands and sticks to all the rules of Doppler, these data may be misleading and incorrect.

Recently in paediatric practice, a miniature TOE probe enabling multiplane 2-D imaging has been introduced (Philips, Andover, Massachusetts, USA). The 48-element transducer measures $8.2 \times$ $7 \mathrm{~mm}$ in diameter at the tip with a $5.2 \mathrm{~mm}$ diameter shaft. This technology allows diagnostic intra-operative TOE assessment of children and neonates as small as $2-2.5 \mathrm{~kg}{ }^{(31)}$

\section{INDICATIONS AND PRACTICE GUIDELINES}

Early experience with the use of peri-operative echocardiography was obtained from its application in cardiac anaesthetic practice; recently however, its role has extended to include non-cardiac surgery and intensive care. ${ }^{(18)}$ In 1996 an American Society of Anaesthesiologists/Society of Cardiovascular Anaesthesiologists Task Force published guidelines on the indications for intra-operative TOE. ${ }^{(32)}$ They divided the indications into three categories based on the strength of supporting evidence or expert opinion that this tool improves clinical outcome:

Category I indications are supported by strong evidence and expert opinion that TOE is indicated, very useful and will improve patient outcome. These category I indications encompass the everyday practice of the intra-operative anaesthetist-echocardiographer and will be discussed in more detail in this review.

- Category II indications are supported by weaker evidence and less expert opinion that TOE will make a difference under these circumstances. Here it may be useful and make a difference to outcome.

- Category III indications have little scientific support or expert opinion that TOE will improve the outcome for patients with these conditions. This is often due to lack of available relevant scientific evidence.

These published guidelines have been updated in $2003^{(33)}$ and has recently been reviewed once again in the USA ${ }^{(34)}$ and Europe (in progress - personal communication). The most striking new change 
is that the Task Force of the American Society of Anaesthesiologists and the Society of Cardiovascular Anaesthesiologists now recommends that "for adult patients without contraindications, TEE should be used in all open heart (e.g. valvular procedures) and all thoracic aortic surgical procedures, and should be considered in CABG surgeries as well". Application of this new standard is dependant on available technology, funding, as well as user knowledge and skills. Categories II and III include most peri-operative situations in the "cardiac surgical patient"; owing to their extensive list, they will not be discussed in this document.

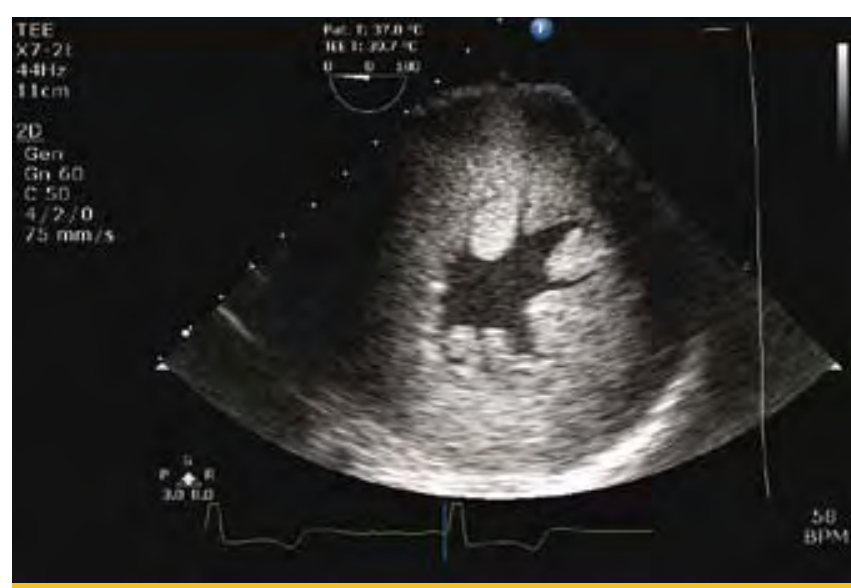

FIGURE Ia: A real-time transgastric short axis view of the left ventricle allows accurate qualitative evaluation of ventricular filling and function and is of great value in acute situations. This image demonstrates a non-compliant left ventricle with severe concentric hypertrophy and preserved systolic function. Should this patient become unstable, volume loading and a higher filling pressure will be the management of choice.

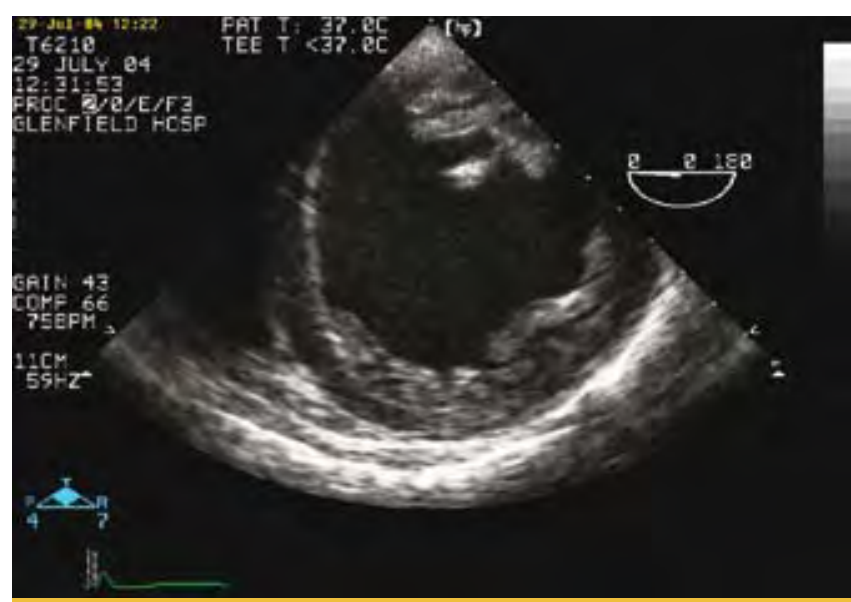

FIGURE I b: A real-time transgastric short axis view of a failing and dilated left ventricle: Should this patient become unstable, inotropic support will be required.

\section{Category I indications}

Life-threatening, persistent haemodynamic instability in the acute setting is an important indication for TOE. The use of a pulmonary artery (PA) catheter in combination with the thermodilution technique has been common in such situations. ${ }^{(35)}$ However, there is no conclusive evidence to date that using a PA catheter improves outcome in critically ill patients. ${ }^{\left({ }^{36}\right)}$ During haemodynamic evaluation TOE has proved reliable and comparative with the PA catheter and standard thermodilution techniques. ${ }^{(37)}$ It can provide a real time and quick analysis of cardiovascular dysfunction and its use prior to other forms of invasive monitoring has been suggested. ${ }^{(38)}$ A survey has shown that among anaesthesiologists with echocardiography training in the USA and Canada, TOE was preferred as monitor to the PA catheter in critically ill patients and complex cardiovascular surgery. ${ }^{(39)}$ TOE examination may provide information quicker and less invasive than the PA catheter and can avoid uncertainty when the cause of instability is unclear or resistant to treatment. It will also provide more extensive real time information with regards to heart function and structure. However, when data from both a PA catheter and TOE are available, they should be viewed as complementary. ${ }^{(40)}$

Visualisation of left ventricular and right ventricular function, interpreting regional wall motion abnormalities and detection of global systolic or diastolic dysfunction can assist the trained clinician. Real-time echocardiography images of ventricular filling, ejection and cardiac structures allows accurate qualitative evaluation of cardiac output, and is of great value in acute situations (Figure la, Figure Ib). Intermittent quantification of cardiac output by TOE may be obtained by measuring the Doppler velocity of blood flow across a specific valve (e.g. the aortic valve). Studies show that the 95\% level of agreement of measurements of cardiac output estimated by TOE and also by thermodilution is within I litre $\mathrm{min}^{-1}$. Whilst these measurements are repeatable within observers, there may be much interobserver variability.

Ischaemic heart disease is an important cause of peri-operative morbidity and mortality. Compared with monitoring of myocardial ischaemia by ECG and S-T segment analysis, TOE enables earlier identification. ${ }^{(41)}$ Early myocardial ischaemia may be detected by visualising loss of normal systolic wall thickening and inward motion, in transverse and longitudinal cross-sectional planes in the transgastric position. ${ }^{\left({ }^{42,43)}\right.}$ Analysis of ventricular segments can elucidate the affected coronary arteries. Following diagnosis, response to therapy or intervention can be assessed in real time by TOE. 


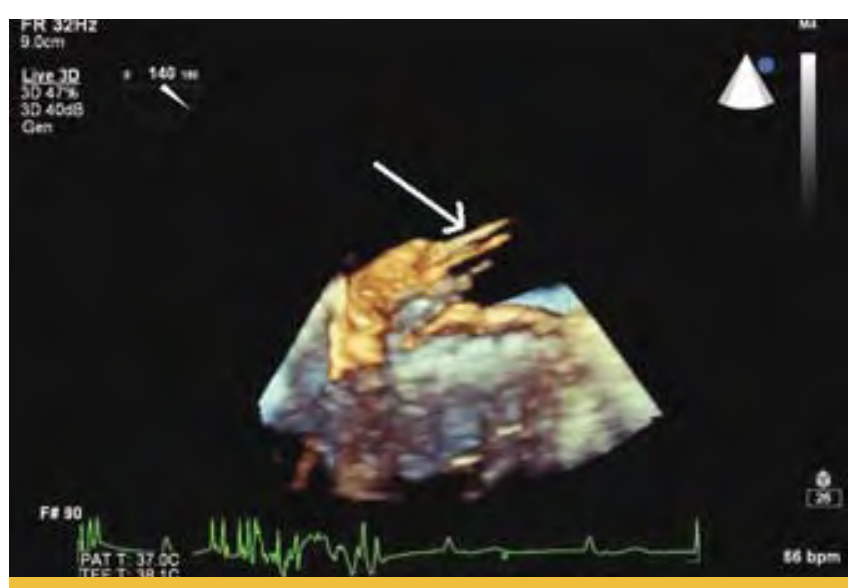

FIGURE 2a: This live 3-D image demonstrates several flail P2 chordae causing severe prolapse of the middle scallop of the posterior mitral valve leaflet.

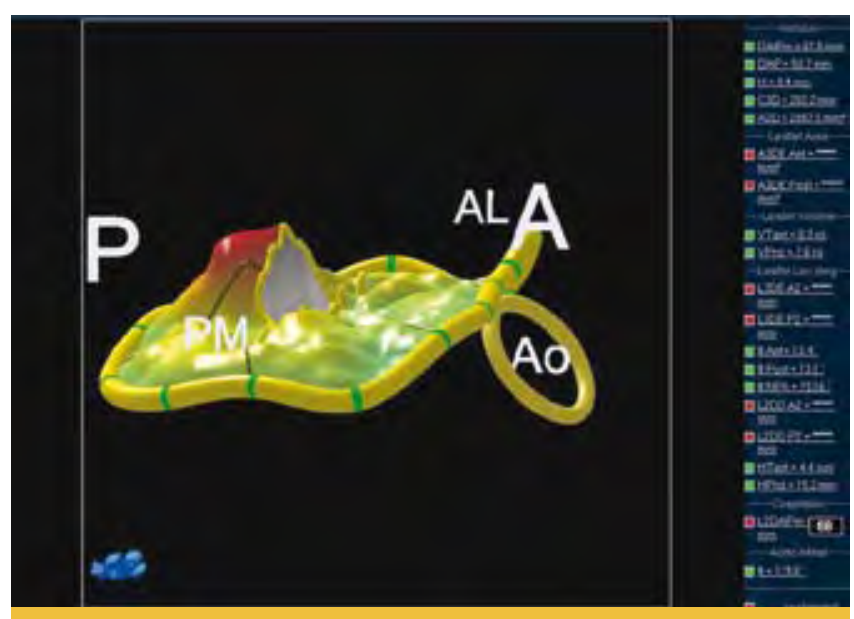

FIGURE 2b: This reconstruction of the same mitral valve provides a graphic image which may assist to quantify the pathology.

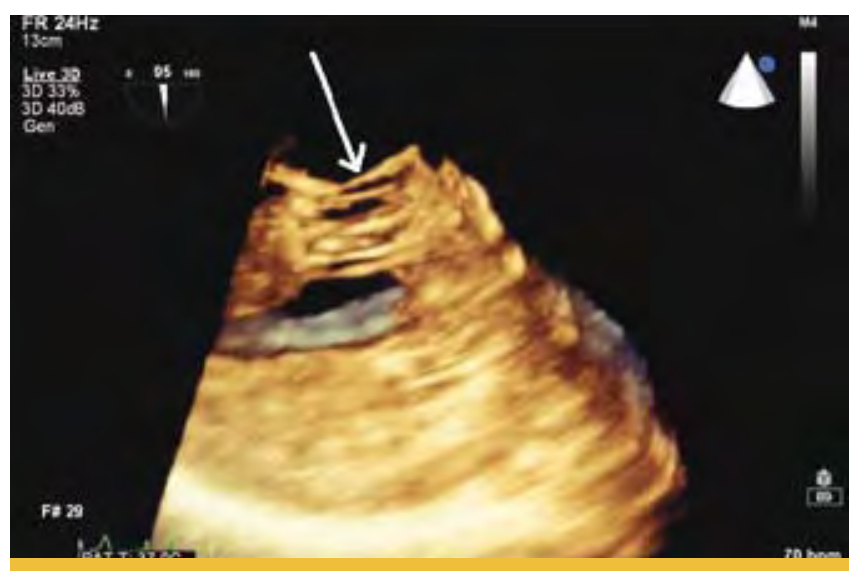

FIGURE 2c: After repair of the same mitral valve with several artificial chordae to the posterior leaflet, either 2-D or 3-D echo can confirm competence in the operating theatre. The artificial chordae are clearly visible on this live 3-D image.
Mitral valve repair and replacement are now performed earlier in disease staging than before. ${ }^{(44)}$ The role of intra-operative TOE for these conditions is well established, ${ }^{(33,45)}$ and has significant impact upon post-operative outcome. ${ }^{(46,47)}$

Owing to the close relationship of the mitral valve to the oesophagus, clear images can be obtained. By using different views and scanning modalities including 3-D TOE, specific leaflet morphology can be identified and pathology quantified ${ }^{(48)}$ (Figure 2a, Figure 2b, Figure 2c). Ventricular dysfunction that has prognostic value may be confirmed by TOE. At the end of surgery, TOE is used to provide quality assurance by checking for residual mitral regurgitation and paraprosthetic leak. ${ }^{(49)}$ (Figure 3a, Figure 3b) In addition to having detailed anatomical knowledge of the mitral valve, echocardiographers have to appreciate that under general anaesthesia there are functional alterations compared with the pre-operative state, e.g. the severity of mitral regurgitation may be underestimated in the operating theatre because of a reduction in preload. ${ }^{(50,51,52)}$

Aortic valve repair procedures are usually complex and require the echocardiographer to have a good understanding of different mechanisms of pathology and possible surgical procedures. ${ }^{(53,54)}$ The vast majority of aortic valves suitable for repair are functionally regurgitant (AR) rather than stenotic. Although the severity of $A R$ is certainly a consideration, identifying its mechanism by TOE may help the surgeon to distinguish those valves suitable for repair from chronic fixed abnormalities requiring aortic valve replacement (Figure 4). A functional classification of mechanisms of aortic regurgitation pathology has been described to assist during $A V$ repair procedures. ${ }^{(55)} \mathrm{A}$ valve sparing procedure involving resuspension of the cusps is often performed in patients with aortic dissection without additional leaflet pathology. Understanding the different mechanisms of $A R$ in a patient with acute type $A$ aortic dissection is essential to guarantee successful surgical outcome ${ }^{(56)}$ (Figure 5a, Figure 5b).

The quality of an aortic valve repair procedure can be assessed early, during cardiopulmonary bypass soon after the aortic cross clamp has been removed. If the repair is unsuccessful, the high aortic pressure due to non-pulsatile bypass flow will cause aortic valve regurgitation, which can be demonstrated by TOE. Residual aortic regurgitation is a poor prognostic indicator of long term outcome and in such cases a second bypass run and replacement of the valve is indicated. 

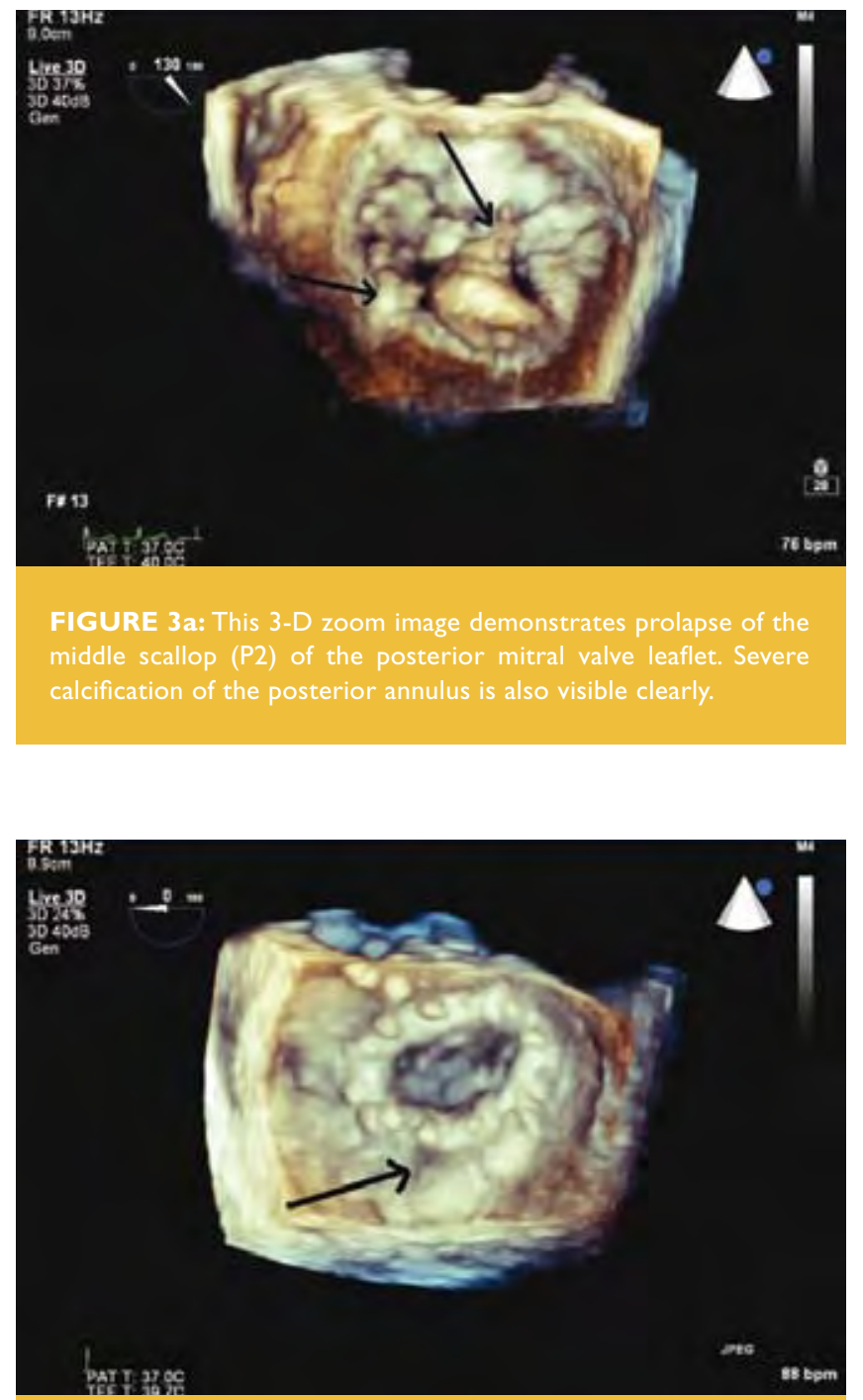

FIGURE 3b: During repair the surgeon commented on the extreme calcification of the annulus. After repair with complete ring prosthesis a high velocity paraprosthesis regurgitant jet was observed. The arrow points at a residual cleft between PI and P2 on the anterolateral side outside the annuloplasty ring.

Although routine valve replacement is considered a category ॥ indication, TOE provides information that can guide modifications of anaesthetic and surgical care which lead to improved outcome. ${ }^{(57)}$ Use of TOE during more complex valve replacement like stentless aortic valve or homograft is invaluable and classed as category 1.(33) These prostheses require surgical experience and accurate intra-operative TOE analysis such as precise diameter measurements of the aortic root and ascending aorta as well as the origin of the coronary ostia. ${ }^{(58,59)}$ Discrepancy between measurements due to dilatation of the ascending aorta may lead to tethering and splaying of the stentless prosthetic leaflets after implantation, which may result in AR. Considering these variations in pathology, the surgeon will then have to replace or remodel the sinotubular junction and or part of the ascending aorta. After AV replacement with a homograft or stentless valve immediate postbypass TOE is used to evaluate leaflet mobility and coaptation. The prosthesis inside the native root will have the appearance of a "tube within a tube", often with a potential space where the different layers of sinus of Valsalva wall and prosthesis overlap. Any turbulent flow pattern on colour Doppler may indicate valve malposition due to imprecise sizing and implantation.

The Ross procedure involves the replacement of a diseased aortic valve, usually in the younger age group, with the patient's own pulmonary autograft. ${ }^{(60)}$ The pulmonary valve is then replaced with a cryopreserved homograft. Accurate pre- and post-surgical assessment of the aortic and pulmonary anatomy is essential for these procedures. Left ventricular contractility and regional wall function should be carefully evaluated for any sign of ischaemia, because the first septal perforator of the left anterior descending coronary artery can be damaged during harvesting of the pulmonary valve.

Acute dissection of the ascending aorta needs emergency surgical intervention. TOE can provide real time evaluation of aortic pathology in the operating theatre, which may be advantageous over the transportation of an unstable patient to potentially remote environments such as $\mathrm{CT}$ or MRI suites. Acute dissection with aortic valve involvement therefore falls in the category I group of indi-

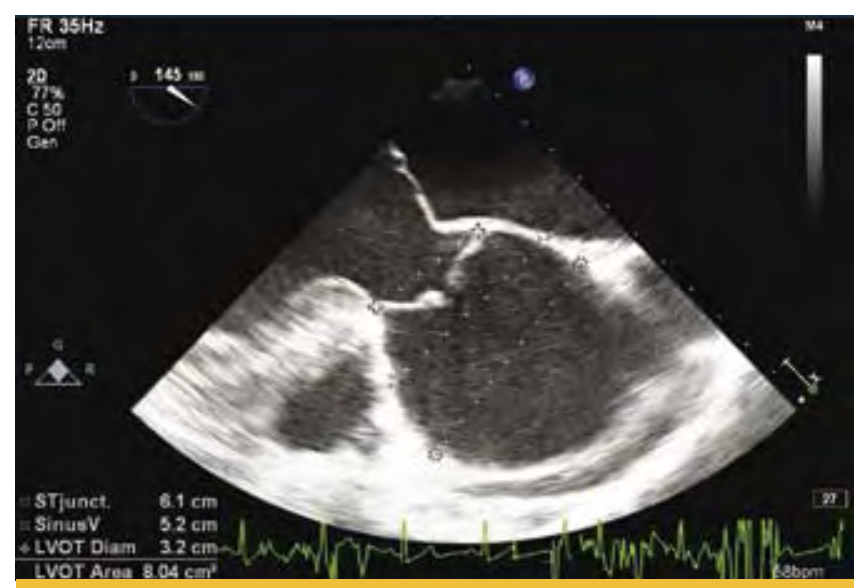

FIGURE 4: Accurate measurements of the aortic root are necessary to guide surgical repair of the aortic valve. In this patient the left ventricular outflow tract diameter measures large at $3.2 \mathrm{~cm}$, while the sinotubular junction is dilated at $6.1 \mathrm{~cm}$ diameter. This means that the surgeon needs to address both the ascending aorta and annulus. 


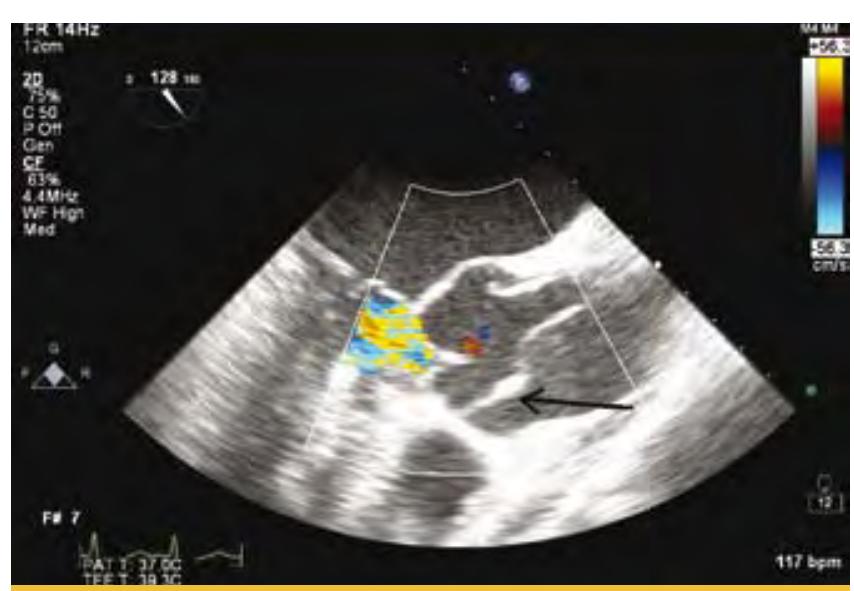

FIGURE 5a: In this patient with a dissection of the ascending aorta, the intimal flap dissects down towards the aortic root involving the ostium of the right coronary artery. The aortic valve is incompetent as demonstrated with colour flow Doppler.

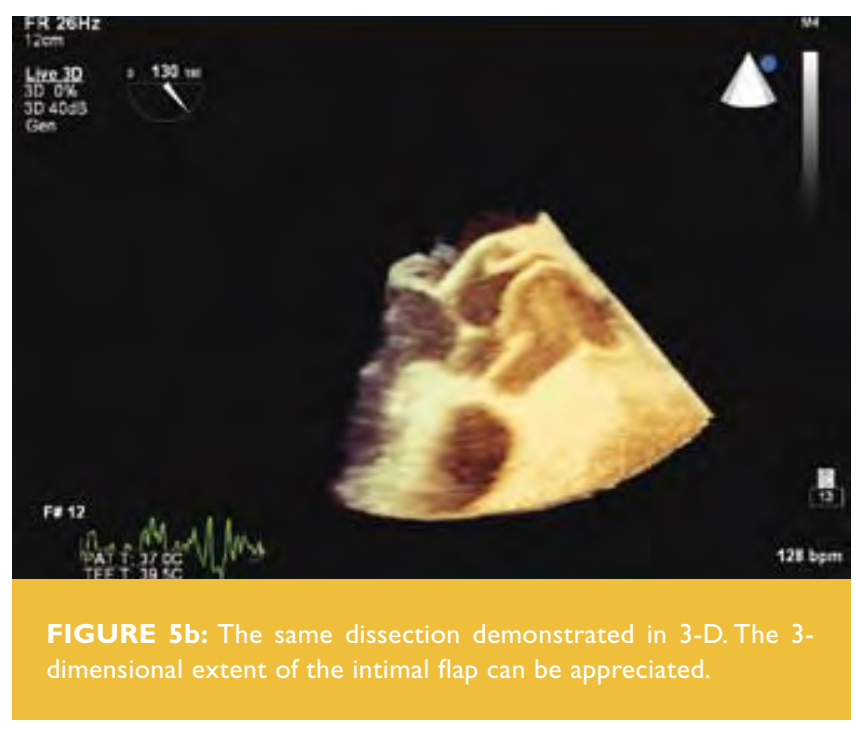

cations. TOE is more sensitive than trans-thoracic echo (TTE) for detection of thoracic aortic dissection and has similar sensitivity and specificity to $\mathrm{CT}$ and MRI imaging. ${ }^{(61)}$

Rapid intra-operative assessment of the aorta is necessary to successfully guide the surgeon. The ascending and descending aorta should be visualised to demonstrate the true lumen, false lumen, intimal flap and entry site. TOE can image the ascending aorta but is limited due to the anatomical location of the trachea and left main stem bronchus, which lies between the oesophagus and aortic arch. As only $80 \%$ of the ascending aorta may be clearly visualised, it is often difficult to examine the proximal $\operatorname{arch}^{(62)}$ and epi-aortic scanning may be indicated. ${ }^{(63)}$
In addition to diagnosing the extent of dissection, TOE is valuable to assess other complications. Involvement of the aortic valve and presence of a pleural or pericardial effusion with a possible tamponade has important prognostic implications (Figure 5a, Figure 5b). Impaired ventricular function and wall motion abnormalities can be evaluated and haemodynamic performance optimised in the unstable patient. Dissection extending into the coronary arteries can be diagnosed with reasonable accuracy because TOE visualises approximately $70-88 \%$ of the left, and $25-50 \%$ of the right coronary artery ostia. ${ }^{(64)}$ TOE is also helpful in the operating theatre during cannulation for cardiopulmonary bypass in patients with acute Type A dissection. For example, when the transapical approach is used, real time imaging assists in guiding the cannula across the left ventricular outflow tract and aortic valve, and ensures correct positioning into the true lumen. ${ }^{(65)}$

Intra-operative TOE is essential for congenital heart surgery i.e. a category I indication. $33,66,67,68)$ Prior to surgery TOE may display clearer images than those of transthoracic echocardiography in patients with pulmonary disease or chest deformities. Cardiac structural abnormalities can be demonstrated and functional haemodynamic limitations can be measured. ${ }^{(69)}$ Whether it is an anaesthetist or cardiologist, it is important that the physician performing intra-operative paediatric TOE examinations is experienced and has a proper understanding of congenital cardiac pathology and the intra-operative conditions. ${ }^{(70)}$

A complete sequential segmental TOE analysis is recommended, similar to the full pre-operative transthoracic assessment in any patient with congenital heart disease. ${ }^{(71)}$ Moreover, in patients with intra- or extracardiac shunt it may be useful to calculate shunt ratio between the pulmonary and systemic circulations. ${ }^{(72)}$ After cardiopulmonary bypass, TOE has been shown to provide initial quality assurance of the surgery. ${ }^{(73)}$ Recently, there have been advances in 3-D TOE for adolescents, ${ }^{(74)}$ as well as multiplane technology which can now be applied in children as small as $2 \mathrm{~kg} .{ }^{(31)}$ A realistic problem with TOE in small children is possible probe compression of the airway and big vessels, leading to desaturation ${ }^{(75)}$ and haemodynamic compromise. ${ }^{(76)}$

Hypertrophic cardiomyopathy (HCM) can be diagnosed with TOE and also falls in the category I of indications. ${ }^{(77)}$ Abnormal motion of the anterior leaflet of the mitral valve onto a hypertrophic interventricular septum during late systole leads to a high pressure gradient across the left ventricular outflow tract as well as dynamic 
mitral regurgitation. ${ }^{(78)}$ If the patient undergoes surgical myomectomy, intra-operative TOE provides information on specific location for myomectomy as well as post-surgical integrity of the interventricular septum, mitral valve function, and patency of the left ventricular outflow tract.

TOE is an essential tool during surgical intervention for endocarditis. ${ }^{(33)}$ It reveals pathology such as vegetations, abscesses and degree of extension to perivalvular tissue. Although more invasive than transthoracic echocardiography, TOE provides better views and has a higher sensitivity for detecting paravalvular abscesses, and vegetations (87-100\%) on native and prosthetic valves. ${ }^{(79)}$

Although the diagnosis of pericardial effusions and use of TOE during pericardial surgery falls in category 2 , the task force has classed it as category I in patients with posterior or loculated effusions, when TOE is used to evaluate the adequacy of a pericardial window procedure. ${ }^{(32,33)}$ In spite of limited scientific evidence, it is expert opinion that TOE is beneficial during these procedures if it helps to avoid serious haemodynamic complications. ${ }^{\left({ }^{(80)}\right.}$

Placement of intracardiac devices and monitoring of their position during port-access and other cardiac surgical interventions are also category I indications. For example, due to complex interaction of $\mathrm{RV}$ and LV function, and importance of correct positioning of LV assist device cannulae, it has been demonstrated that TOE guidance improves cardiac performance during placement of mechanical support devices. ${ }^{\left({ }^{11}\right)}$

\section{Category II and III indications}

It is interesting that according to the 2003 ACC/AHA/ASE guidelines, the only category III indication for peri-operative echocardiography is surgical repair of uncomplicated secundum atrial septal defect. ${ }^{(33)}$ Under category II falls the rest of the cardiac conditions, procedures and interventions when the patient may be at risk of ischaemia or haemodynamic instability. The feeling among most anaesthetic echocardiographers is that many Categories II and III indications may well be upgraded to Category I in future when more relevant scientific evidence becomes available. ${ }^{(34)}$ Absence of evidence is not necessarily evidence of absence.

\section{Complications and contra-indications}

Complication rates and mortality associated with the use of TOE are extremely low. Data for complications attributable to
TOE are derived from cardiac anaesthetic practice. In a case series of 4784 patients, six complications were detected, giving an incidence of $0.13 \%{ }^{(82)}$ This rate is similar to that of another case series examining 7200 patients where TOE-associated morbidity and mortality was $0.2 \%$ and $0 \%$ respectively. ${ }^{(83)}$ Typical injuries include a sore throat, dental injury, upper gastrointestinal haemorrhage and oesophageal perforation. Equipment familiarity and an experienced anaesthetic team avoid perhaps one of the most important potential complications - the anaesthetist's attention being distracted from patient care. The benefits of peri-operative echocardiography should therefore be weighed against the risks that it poses. ${ }^{(84)}$

There are few absolute contra-indications. Recent oesophageal surgery, oesophageal strictures, diverticulae and tumours will be contra-indications. However, TOE may be used for patients with oral, oesophageal or gastric disease, if the expected benefit outweighs the potential risk, and provided appropriate precautions are taken (e.g. smallest possible probe).(34) Anti-coagulation with warfarin or heparin within the therapeutic range can only be considered a very relative contra-indication.

\section{TRAINING AND QUALITY ASSURANCE}

A substantial level of training is required to obtain maximum benefit from TOE as a high quality peri-operative monitor and diagnostic tool. The development of training and certification in echocardiography has been a long and intensive process in Europe and the USA. Excellent comprehensive TOE courses have been developed, ${ }^{\left({ }^{85}\right)}$ and working groups on TOE have published extensive practice and training guidelines on both sides of the Atlantic and in Japan. ${ }^{(86,87)}$ The American Society of Cardiothoracic Anaesthesiologists (SCA) developed the first formal examination in peri-operative TOE in 1998. ${ }^{(88)}$ The SCA and American Society of Echocardiography (ASE) then combined forces to establish the National Board of Echocardiography, which had the responsibility to further administer examinations and develop a certification process in clinical echocardiography. ${ }^{(89)}$

Europe has followed a similar route with the Association of Cardiothoracic Anaesthetists of Great Britain and Ireland (ACTA) joining forces with the British Society of Echocardiography (BSE) to establish an accreditation process in TOE with its first examination held in the UK in 2003.(90) Since then the European Association of Cardiothoracic Anaesthesiologists (EACTA) and the European Association of Echocardiography (EAE) produced its own Euro- 
pean TOE examination and accreditation process in 2005. In 2004, the Japanese Society of Cardiovascular Anaesthesiologists launched its first TOE competency examination. The purpose of these accreditation processes is to enable recognition of special competence in peri-operative echocardiography against an objective standard. All accreditation processes consist of two parts. With the practical part the candidate must demonstrate adequate training and competency through a supervised residency program or logbook. The theoretical part requires the successful completion of a multiple choice and image clip examination.

In the case of anaesthetists, traditional TOE training is performed in the operating room during a cardiac surgical procedure with its time constraints and limitations e.g. electrocautery interference. Recently a commercial TOE simulator has been developed (Heartworks) which allows the examination of a mannequin with a realistic "digital" TOE probe.(91) This simulator greatly simplifies teaching of probe manipulations and image acquisition of normal anatomy, and has enormous potential for training. Continuous improvement of quality of peri-operative echocardiography should be pursued not only by individual practitioners, but also by echocardiography departments. ${ }^{(92,93)}$

\section{CONCLUSION}

Cardiac surgery and anaesthesia have come a long way since the late 1970s when TOE was introduced into the peri-operative arena. The development of many cardiac surgical procedures and the reduction in peri-operative morbidity and mortality can be directly related to the use ofTOE. ${ }^{(94)}$

Furthermore, as our expectations for improved peri-operative outcomes continue to rise, we envisage that we will, in future, see an increase in the application of TOE for major non-cardiac surgery as well as for intensive care. With improvements in training, software, miniaturisation of technology and availability of affordable basic echocardiographic equipment, it is likely that this aspiration will be fulfilled.

\section{REFERENCES}

References

I. Frazin L, Telano JV, Stephanides L, et al. Oesophageal echocardiography. Circulation 1976;54:102-8.

2. Hillel Z, Mikula BS, Thys D.The Current State of Intra-operative Echocardiography in North America: Result of a Survey. J Cardiothorac Anaesth 1988;803-I I.

3. Morewood GH, Gallagher ME, Gaughan JP, et al. Current practice patterns for peri-operative transoesophageal echocardiography in the United States. Anesthesiology $2001 ; 95: 1507-12$.

4. Kneeshaw JD. Transoesophageal echocardiography (TOE) in the operating room. Brit J Anaesth 2006;97:77-84.

5. Bergquist $\mathrm{BD}$, Bellows WH, Leung JM. Transoesophageal Echocardiography in Myocardial Revascularisation: Influence on Intra-operative Decisionmaking. Anaesth Analg 1996;82:1 | 39-45.

6. Kolev N, Brase R, Swanevelder J, et al. The influence of transoesophageal echocardiography on intra-operative decision-making. Anaesthesia 1998;53:767-73.

7. Click RL, Abel MD, Schaff HV. Intra-operative transoesophageal echocardiography: 5-year prospective review of impact on surgical management. Mayo Clin Proc 2000;75: 241-7.

8. Michel-Cherqui M, Ceddaha A, Liu N, et al. Assessment of systematic use of intraoperative transoesophageal echocardiography during cardiac surgery in adults: a prospective study of 203 patients. J Cardiothoracic Vasc Anes 2000; 14: 45-50.

9. Couture P, Denault AY, McKenty S, et al. Impact of routine use of intra-operative transoesophageal echocardiography during cardiac surgery. Can J Anaesth 2000;47:20-6

10. Mishra M, Chauhan R, Sharma KK, et al. Real-time intra-operative transoesophageal echocardiography. How useful? Experience of 5016 cases. J Cardiothorac Vasc Anes 1998; 12:625-32.

11. Fanshawe M, Ellis C, Habib S, et al. A retrospective analysis of the costs and benefits related to alterations in cardiac surgery from routine intra-operative transoesophageal echocardiography. Anaesth Analg 2002;95:824-7.

12. Bettex DA, Pretre $R$, Jenni $R$, et al. Cost-effectiveness of routine intra-operative transoesophageal echocardiography in pediatric cardiac surgery: a 10 year experience. Anaesth Analg 2005; 100: 127 1-5.

13. Eltzschig HK, Rosenberger P, Loffler M, et al. Impact of intra-operative transoesophageal echocardiography on surgical decisions in 12566 patients undergoing cardiac surgery. Ann Thor Surg 2008;85:845-52.

14. Heidenreich PA. Transoesophageal echocardiography (TEE) in the critically ill patient. Cardiol Clin 2000; 18:789-805.

15. Karski JM. Transoesophageal echocardiography in the intensive care unit. Sem Cardiothorac Vasc Anes 2006; 10:162-166

16. Mahmood F, Christie A, Matyal R. Transoesophageal echocardiography and noncardiac surgery. Semin Cardiothorac Vasc Anaesth 2008; I2(4):265-89.

17. Mittnacht AJC, Fanshawe M, Konstadt S. Anaesthetic Considerations in the patient with valvular heart disease undergoing non-cardiac surgery. Semin Cardiothorac Vasc Anaesth 2008; 12:33-59.

18. Ng A, Swanevelder J. Peri-operative echocardiography for non-cardiac surgery: what is its role in routine haemodynamic monitoring? $\mathrm{Br}$ J Anaesth 2009; 102(6): $73 \mid-4$.

19. Schulmeyer MCC, Santelices E, Vega R, et al. Impact of intra-operative transoesophageal echocardiography during non-cardiac surgery. J Cardiothorac Vasc Anaesth 2006;20:768-71.

20. Hofer CK, Zollinger A, Rak M, et al. Therapeutic impact of intra-operative transoesophageal echocardiography during non-cardiac surgery. Anaesthesia 2004; 59:3-9. 
21. Shanewise JS, Cheung AT, Aronson S, et al. ASE/SCA Guidelines for performing a comprehensive multiplane transoesophageal echocardiography examination: Recommendations of the American Society of Echocardiography Council for Intra-operative Echocardiography and the Society of Cardiovascular Anaesthesiologists Task Force for Certification in Peri-operative Transoesophageal Echocardiography. Anaesth Analg 1999;89:870-84.

22. Flachskampf FA, Decoodt P, Fraser AG, et al. Guidelines from the Working Group: Recommendations for performing transoesophageal echocardiography Eur J Echocardiography 200 1;2:8-21.

23. Marsan NA, Tops LF, Nihoyannopoulos $P$, et al. Real-time three-dimensional echocardiography: current and future clinical applications. Heart 2009;95: 1881-90.

24. Grewal J, Mankad S, Freeman WK, et al. Real-time three-dimensional transoesophageal echocardiography in the intra-operative assessment of mitral valve disease. J Am Soc Echocardiogr 2009; 22(1): 34-41.

25. Mahmood F, Karthik S, Subramaniam B, et al. Intra-operative application of geometric three-dimensional mitral valve assessment package: a feasibility study. J Cardiothorac Vasc Anaesth 2008; 22(2): 292-8.

26. Scohy TV, Ten Cate F, Lecomte PV, et al. Usefulness of intra-operative real-time 3-D transoesophageal echocardiography in cardiac surgery. J Card Surg 2008 23(6):784-6.

27. Jungwirth B, Mackensen GB. Real-time 3-dimensional echocardiography in the operating room. Semin Cardiothorac Vasc Anaesth 2008; 12(4):248-64.

28. Shernan SK. Intra-operative three-dimensional echocardiography: ready for primetime? J Am Soc Echocardiogr 2009; 22(1): 27A-28A.

29. Skubas N. Intra-operative Doppler tissue imaging is a valuable addition to cardiac anaesthesiologists' armamentarium: a core review. Anaesth Analg 2009;108(I) 48-66.

30. Tousignant C. Con: Intra-operative Doppler tissue imaging is a valuable addition to cardiac anaesthesiologists' armamentarium. Anaesth Analg 2009; 108(I):41-7.

31. Scohy TV, Gommers D, ten Harkel ADJ, et al. Intra-operative evaluation of micromultiplane transoesophageal echocardiographic probe in surgery for congenital heart disease. Eur J Echocardiogr 2007;8:241-246.

32. Thys DM, Abel M, Bollen BA, et al. Practice Guidelines for peri-operative transoesophageal echocardiography. A report by the American Society of Anaesthesiologists and the Society of Cardiovascular Anaesthesiologists Task Force on transoesophageal echocardiography. Anaesthesiology 1996;84:986-1006.

33. Cheitlin MD, Armstrong WF, Aurigemma GP, et al. ACC/AHA/ASE 2003 guideline update for the clinical application of echocardiography - summary article: a report of the American College of Cardiology/American Heart Association Task Force on Practice Guidelines. Circulation 2003; 108: 1 | 46-62.

34. Thys DM, Abel MD, Brooker RF, et al. On behalf of the American Society of Anaesthesiologists and the Society of Cardiovascular Anaesthesiologists. Practice Guidelines for Peri-operative Transoesophageal Echocardiography. An Updated Report by the American Society of Anaesthesiologists and the Society of Cardiovascular Anaesthesiologists Task Force on Transoesophageal Echocardiography. 2010, currently; www.scahq.org

35. Cooper AB, Doig GS, Sibbald WJ. Pulmonary artery catheters in the critically ill. An overview using the methodology of evidence-based medicine. Crit Care Clin 1996; 12:777-94.

36. Harvey S, Harrison DA, Singer M, et al. Assessment of clinical effectiveness of pulmonary artery catheters in management of patients in intensive care (PACMAN): a randomised controlled trial. Lancet 2005;366:472-7.

37. Tousignant CP, Walsh F, Mazer CD. The use of TEE for preload assessment in critically ill patients. Anaesth Analg 2000;90:35 I-5.
38. Poelaert J, Schmidt C, Colardyn F. Transoesophageal echocardiography in the critically ill. A review of the literature. Anaesthesia 1998;53:55-68.

39. Jacka MJ, Cohen MM, To T, et al. The use of and preferences for the transoesophageal echocardiogram and pulmonary artery catheter among cardiovascular anaesthesiologists. Anaesth Analg 2002;94: 1065-71.

40. Maslow A, Bert A, Schwartz C, et al. Transoesophageal Echocardiography in the non-cardiac surgical patient. Int Anaesthesiol Clin 2002;40(I):73- 132

4I. Kolev N, Ihra G, Swanevelder J, et al. Biplane transoesophageal echocardiographic detection of myocardial ischaemia in patients with coronary artery disease undergoing non-cardiac surgery: segmental wall motion vs. electrocardiography and haemodynamic performance. Eur J Anaesthesiol 1997;14(4):412-20.

42. Smith JS, Cahalan MK, Benefiel DJ, et al. Intra-operative detection of myocardial ischaemia in high risk patients: electrocardiography versus two-dimensional transoesophageal echocardiography. Circulation 1985;72: 1015-21.

43. Rouine-Rapp K, lonescu P, Balea M, et al. Detection of intra-operative segmental wall-motion abnormalities by transoesophageal echocardiography: the incremental value of additional cross sections in the transverse and longitudinal planes. Anaesth Analg 1996;83:1 |41-8.

44. Shuhaiber J, Anderson RJ: Meta-analysis of clinical outcomes following surgical mitral valve repair or replacement. Eur J Cardiothorac Surg 2007; 31 (2): 267-75.

45. Kawano H, Mizoguchi T, Ayoagi S. Intra-operative transoesophageal echocardiography for evaluation of mitral valve repair. J Heart Valve Dis 1999;8:287-93.

46. Shapira $Y$, Vaturi $M$, Weisenberg DE, et al.: Impact of intra-operative transoesophageal echocardiography in patients undergoing valve replacement. Ann Thorac Surg 2004; 78(2): 579-83; discussion 583-4.

47. Fischer GW, Anyanwu AC, Adams DH. Intra-operative classification of mitra valve dysfunction: The role of the anaesthesiologist in mitral valve reconstruction. J Cardiothorac Vasc Anaesth 2009;23(4):531-43.

48. Salcedo EE, Quaife RA, Seres T, et al. A framework for systematic characterisation of the mitral valve by real-time three-dimensional transoesophageal echocardiography. J Am Soc Echocardiogr 2009;22: 1087-99.

49. Saiki $Y$, Kasegawa $H$, Kawase $M$, et al. Intra-operative TEE during mitral valve repair: does it predict early and late post-operative mitral valve dysfunction? Ann Thorac Surg 1998;66:1277-81.

50. Grewal KS, Malkowski MJ, Piracha AR, et al. Effect of general anaesthesia on the severity of mitral regurgitation by transoesophageal echocardiography. Am Cardiol 2000;85(2):99-203.

51. Matyal R. Pro: Mitral regurgitation can be reliably assessed under general anaesthesia. J Cardiothorac Vasc Anaesth 2009;23(4):555-57.

52. Banks D. Con: Mitral regurgitation can be reliably assessed under general anaesthesia. J Cardiothorac Vasc Anaesth 2009;23(4):558-60.

53. Hopkins RA. Aortic valve leaflet sparing and salvage surgery: evolution of techniques for aortic root reconstruction. Eur J Cardiothoracic Surg 2003;24: 886-897.

54. Yacoub $\mathrm{MH}$, Cohn LH. Novel approaches to cardiac valve repair: from structure to function: part II. Circulation 2004; 109: I064- 1072.

55. El Khoury G, Glineur D, Rubay J, et al. Functional classification of aortic root/ valve abnormalities and their correlation with etiologies and surgical procedures. Curr Opinion Cardiol 2005;20:1 15-121.

56. Movsowitz HD, Levine RA, Hilgenberg AD, et al. Transoesophageal Echocardiographic description of the mechanisms of aortic regurgitation in acute type $A$ aortic dissection: implications for aortic valve repair. J Am Coll Cardiol 2000;36: 884-890. 
57. Qizilbash B, Couture P, Denault A. Impact of peri-operative transoesophageal echocardiography in aortic valve replacement. Semin Cardiothorac Vasc Anaesth 2007; I I (4):288-300

58. Bach DS. Echocardiographic assessment of stentless aortic bioprosthetic valves. J Am Soc Echocardiogr 2000; 13:941-948.

59. Akar AR, Szafranek A, Alexiou C, et al. Use of stentless xenografts in the aortic position: determinants of early and late outcome. Ann Thorac Surg 2002;74(5): 1450-7.

60. Rubay JE, Buche M, El Khoury GA, et al. The Ross operation: Mid-term results. Ann Thorac Surg 1999;67:1355-1358.

61. Nienaber CA, von Kodolitsch $Y$, Nicholas $V$, et al. The diagnosis of thoracic aortic dissection by non-invasive imaging procedures. N Engl J Med 1993; I:328.

62. Konstadt SN, Reich DL, Quintana C, et al. The ascending aorta: how much does transoesophageal echocardiography see? Anaesth Analg 1994;78:240-4.

63. Glas KE, Swaminathan M, Reeves ST, et al. Guidelines for the performance of a comprehensive intra-operative epiaortic ultrasonographic examination: Recommendations of the American Society of Echocardiography and the Society of Cardiovascular Anaesthesiologists; endorsed by the Society of Thoracic Surgeons. Anaesth Analg 2008; 106(5): 1376-84.

64. Ballal RS, Nanda NC, Gatewood R, et al. Usefulness of transoesophageal echocardiography in assessment of aortic dissection. Circulation 1991;84:1903-14.

65. Sosnowski AW, Jutley RS, Masala N, et al. How I do it: transapical cannulation for acute type-A aortic dissection. J Cardiothorac Surg 2008;3:4.

66. Ramamoorthy C. Lynn AM. Stevenson JG. Pro: transoesophageal echocardiography should be routinely used during pediatric open cardiac surgery. J Cardiothorac Vasc Anaesth 1999; 13(5):629-31

67. Stevenson JG. Role of transoesophageal echocardiography during repair of congenital cardiac defects. Acta Paediatr. Suppl. 1995;41 0:23-33.

68. Ayres NA, Miller-Hance W, Fyfe DA, et al. Indications and guidelines for performance of transoesophageal echocardiography in the patient with pediatric acquired or congenital heart disease. J Am Soc Echocardiogr 2005; 1 8:91-8.

69. Ungerleider RM, Kisslo JA, Greeley WJ et al. Intra-operative echocardiography during congenital heart operations: experience from I 000 cases. Ann Thorac Surg 1995;60(6 Suppl):S539-42.

70. Stevenson JG. Adherence to physician training guidelines for pediatric transoesophageal echocardiography affects the outcome of patients undergoing repair of congenital cardiac defects. J Am Soc Echocardiogr 1999; I 2(3): I65-72.

71. Shinebourne EA, McCartney FJ, Anderson RH. Sequential chamber localisation: logic approach to diagnosis in congenital heart disease. Br Heart J 1976;38:327.

72. Valdez-Cruz LM, Horowitz S, Mesel E, et al. A pulsed Doppler echocardiographic method for calculating pulmonary and systemic blood flow in atrial level shunts: validation studies in animals and initial human experience. Circulation 1984;69-86

73. Sheil ML, Baines DB. Intra-operative transoesophageal echocardiography for paediatric cardiac surgery - an audit of 200 cases. Anaesth Intensive Care 1999;27:59|-5.

74. Baker GH, Ringewald JM, Hsia TY, et al. Usefulness of live three-dimensional transoesophageal echocardiography in a congenital heart center. Am J Cardiol 2009; 104(5):739.

75. Andropoulos DB, Ayres NA, Stayer SA, et al. The effect of transoesophageal echocardiography on ventilation in small infants undergoing cardiac surgery. Anaesth Analg 2000;90:47-9.

76. Andropoulos DB, Stayer SA, Bent ST, et al. The effects of transoesophageal echocardiography on haemodynamic variables in small infants undergoing cardiac surgery. J Cardiothorac Vasc Anaesth 2000; 1 4:133-5.
77. Maron BJ, McKenna WJ, Danielson GK, et al. ACC/ESC clinical expert consensus document on hypertrophic cardiomyopathy: a report of the American College of Cardiology Task Force on Clinical Expert Consensus Docoments and the European Society of Cardiology Committee for Practice Guidelines. Eur Heart J 2003;24:1965-91

78. Kaple RK, Murphy RT, DiPaola LM, et al. Mitral valve abnormalities in hypertrophic cardiomyopathy: echocardiographic features and surgical outcomes. Ann Thor Surg 2008;85: 1527-35.

79. Shapiro SM. Transoesophageal echocardiography in the diagnosis of infective endocarditis. Chest 1994; 105:377-82.

80. Schmidlin D, Schuepbach R, Bernard E, et al. Indications and impact of postoperative transoesophageal echocardiography in cardiac surgical patients. Critical Care Medicine 200 I;29(1 I):2143-8.

81. Scohy TV, Gommers D, Maat AP, et al. Intra-operative transoesophagea echocardiography is beneficial for haemodynamic stabilisation during left ventricular assist device implantation in children. Paediatr Anaesth 2009;19(4):390-5.

82. Kallmeyer IJ, Collard CD, Fox JA, et al. The safety of intra-operative transoesphageal echocardiography: a case series of 7200 cardiac surgical patients. Anaesth Analg 2001;92:1126-30.

83. Piercy M, McNicol L, Dinh DT, et al. Major complications related to the use of transoesophageal echocardiography in cardiac surgery. J Cardiothorac Vasc Anaesth 2009;23:62-5

84. Côté G, Denault A. Transoesophageal echocardiography-related complications. Can J Anaesth 2008;55:622-47.

85. Savage $R$, Licina $M$, Koch $C$, et al. Educational program for intra-operative transoesophageal echocardiography. Anaesth Analg 1995;81:399-403.

86. Pearlman AS, Gardin JM, Martin RP, et al. Guidelines for physician training in transoesophageal echocardiography: recommendations of the American Society of Echocardiography Committee for Physician Training in Echocardiography. J Am Soc Echocardiogr 1992;5: 187-94.

87. Thys DM. Training, certification and credentialling in transoesophageal echocardiography. J Cardiothorac Vasc Anaesth 1996; 10:309-10.

88. Aronson S, Butler A, Subhiyah R, et al. Development and analysis of a new certifying examination in peri-operative transoesophageal echocardiography. Anaesth Analg 2002;95: 1476-82.

89. Aronson S,Thys DM. Training and certification in peri-operative transoesophageal echocardiography : a historical perspective. Anaesth Analg 200 ; 93 :1422-7.

90. Swanevelder J, Chin D, Kneeshaw J, et al. Accreditation in transoesphageal echocardiography: statement from the Association of Cardiothoracic Anaesthetists and the British Society of Echocardiography Joint TOE Accreditation Committee. $\mathrm{Br}$ J Anaesth 2003:91:469-72.

91. Bose R, Matyal R, Panzica P, et al. Transoesophageal echocardiography simulator: a new learning tool. J Cardiothorac Vasc Anaesth 2009 ;23(4):544-48.

92. Mathew JP, Glas K, Troianos CA, et al. ASE/SCA recommendations and guidelines for continuous quality improvement in peri-operative echocardiography. Anaesth Analg 2006; 103(6): 1416-25.

93. Popescu BA, Andrade MJ, Badano L, et al. European Association of Echocardiography recommendations for training, competence, and quality improvement in echocardiography. Eur J Echocardiogr 2009; 10:893-905.

94. Klein AA, Snell A, Nashef SAM, et al. The impact of intra-operative transoesophageal echocardiography on cardiac surgical practice. Anaesthesia 2009; 64:947-52. 